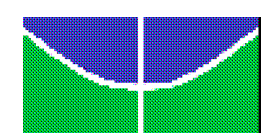

UNIVERSIDADE DE BRASÍLIA - UNB

FACULDADE DE ECONOMIA, ADMINISTRAÇÃO, CONTABILIDADE E CIÊNCIA DA INFORMAÇÃO E DOCUMENTAÇÃO - FACE

PROGRAMA DE PÓS-GRADUAÇÃO EM ADMINISTRAÇÃO (PPGA)

ESPECIALIZAÇÃO EM ORÇAMENTO E FINANÇAS

TRAÇOS DA CULTURA ORGANIZACIONAL DO SERPRO

JOÃO PAULO SOUZA ALVES DE SOUZA

Brasília-DF

2009 
JOÃO PAULO SOUZA ALVES DE SOUZA

\section{OS TRAÇOS DA CULTURA ORGANIZACIONAL DO SERPRO}

Monografia apresentada no Programa de Pós-

Graduação em Administração (PPGA) da

Faculdade de Economia, Administração,

Contabilidade e Ciência da Informação e

Documentação (FACE), da Universidade de

Brasília, para obtenção do grau de Especialista em

Orçamento e Finanças

Orientador: Prof. Dr. Marcus Vinicius Soares

Siqueira

Brasília - DF

2009 


\section{AGRADECIMENTOS}

À Profa. Dr ${ }^{a}$. Maria de Fátima Bruno-Faria, por seu notável comprometimento com o mundo acadêmico e com a produção científica.

À Prof ${ }^{\circ}$. Coordenador do curso Eduardo Raupp, por seu empenho em equacionar conflitos e encontrar sempre alternativas para os alunos e professores do curso.

À Prof ${ }^{\circ}$ Dr ${ }^{o}$. Marcus Vinicius, por sua excelente didática e postura crítica durante as aulas, instigando-nos sempre à desenvolver uma visão mais profunda acerca do contexto organizacional brasileiro e mundial, e também, por ter me dado todo o apoio e orientação necessária neste trabalho.

Ao João e a todos os demais colegas funcionários da Universidade de Brasília, por sua solicitude e seu auxílio na solução de questões burocráticas.

A todos os colegas da Universidade Corporativa do SERPRO, que promoveram $e$ organizaram este curso junto à UnB, além de terem prestado apoio a todos nós alunos, sempre que necessário. Em destaque dentre esses colegas do SERPRO, ao representante de turma e também colega de curso, Josimar Pereira, que foi bastante responsável nessa empreitada e apoiou a todos os colegas do curso sempre que possível.

A todos os colegas de empresa e meus chefes de trabalho Wilton e Reinaldo, que me apoiaram na realização deste estudo, seja na liberação da jornada de trabalho ou na contribuição de conteúdo realizada por meio de entrevista ou documentação corporativa.

Ao meu colega de turma e amigo Marcos Ozório que me apoiou em toda a jornada cansativa do curso, tanto me auxiliando nos trabalhos como me incentivando também.

A todos as pessoas comprometidas com o estudo e produção cientifica e que enxergam no conhecimento e na sua aplicação prática, uma forma de melhorar um mundo tão cheio de desigualdades e injustiças.

À mulher espetacular que preencheu e fez história em minha vida, Gilvana Bastos, que me deu amor, sempre investindo e torcendo por mim, apoiando-me em tudo o que foi necessário.

Por fim, à minha família, a quem amo muito e devo toda a minha história de vida, acertos, erros, fracassos e conquistas neste mundo. 
"A mente que se abre a uma nova idéia jamais voltará a seu tamanho original."

Albert Einstein 


\section{RESUMO}

Este estudo apresenta como ocorrem as relações entre a cultura nacional e a cultura organizacional brasileira, bem como sua mútua influência, com o objetivo de ilustrar em seguida os traços da cultura organizacional do SERPRO e sua relação com os fatores culturais do Brasil. Com base na literatura científica pertinente ao tema, são apresentadas e discutidas diversas concepções teóricas acerca do estilo brasileiro de administrar, focalizando seus principais traços e componentes, ilustrando situações características de contextos organizacionais e sua relação com os traços culturais brasileiros. Foi realizada pesquisa qualitativa de caráter exploratório com a aplicação de Análise de Conteúdo nas entrevistas realizadas. Os resultados das entrevistas e da análise documental possibilitaram a categorização das perspectivas organizacionais da empresa e de seus empregados, relacionando-as com os principais elementos encontrados na administração brasileira e nas raízes de nossa cultura. Conclui-se que a cultura organizacional de uma empresa, principalmente, relacionada ao setor público, ainda sofre muita influência do cenário e estilo político do país, da forma como se dá a gestão pública e da própria história e contexto social do país.

Palavras-Chave: SERPRO, Cultura Nacional, Cultura Organizacional 


\begin{abstract}
This study shows how the relations are between the national culture and organizational culture in Brazil, and their mutual influence, with the aim of illustrating then traces the organizational culture of public company SERPRO and their relationship to cultural factors in Brazil. Based on the literature relevant to the theme are presented and discussed various theoretical conceptions about the Brazilian style of managing, focusing on its main traces and components, illustrating situations organizational contexts and their relationship with the Brazilian cultural traits. An exploratory qualitative research was executed with the application of Content Analysis of the interviews. The results of interviews and documentary analysis allowed the categorization of organizational prospects of the company and its employees, relating them to the main elements found in the Brazilian government and the roots of our culture. It is concluded that the organizational culture of a company, mainly related to the public sector still suffers great influence of the Brazilian political scene, the style of public management and the history and social context of the country.
\end{abstract}

Keywords: SERPRO, National Culture, Organizational Culture 


\section{LISTA DE FIGURAS}

Figura 1 - Visão integrada do sistema de ação cultural brasileiro (modelo proposto)......................22 


\section{LISTA DE TABELAS}

Tabela 1 - Principais Traços culturais presentes na empresa brasileira .........................................23 


\section{LISTA DE QUADROS}

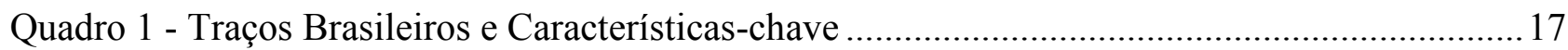

Quadro 2 - Principais Características da Cultura Organizacional................................................... 18

Quadro 3 - Visão sumária dos traços do Sistema de Ação Cultural Brasileiro .................................23

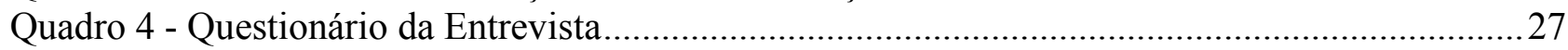

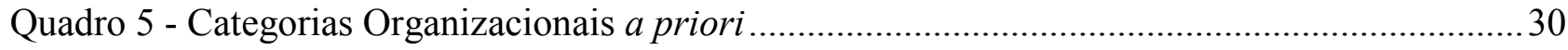

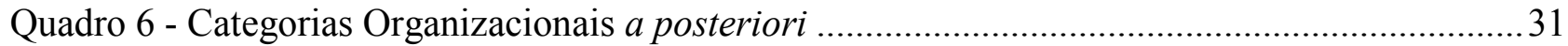

Quadro 7 - Mapeamento dos Traços da Cultura Organizacional do SERPRO.................................32 


\section{LISTA DE SIGLAS E ABREVIATURAS}

SERPRO - Serviço Federal de Processamento de Dados

ACT - Acordo Coletivo de Trabalho

TI - Tecnologia de Informação

GDES - Gerenciamento de Desempenho do Empregado do SERPRO

FCT - Função Comissionada Técnica 


\section{SUMÁRIO}

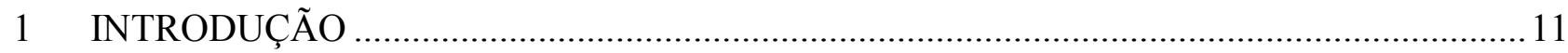

1.1 Contextualização do problema da pesquisa ............................................................. 13

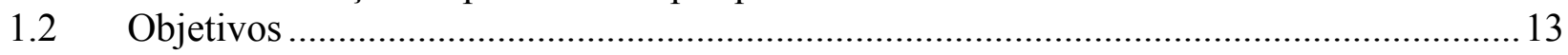

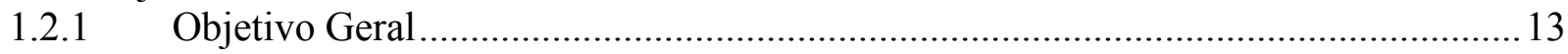

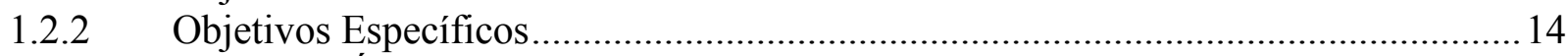

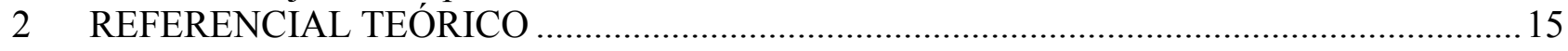

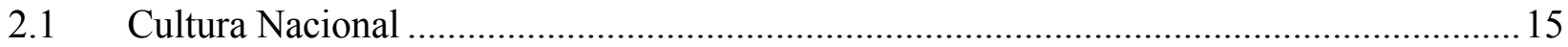

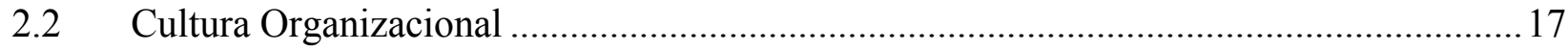

2.3 A relação entre Cultura Nacional e Cultura Organizacional.............................................. 18

2.4 A influência da Cultura Nacional nas organizações ......................................................... 19

2.5 Aspectos da Cultura Organizacional do Serviço Público ...................................................22

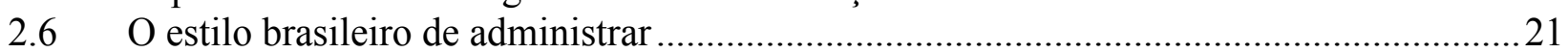

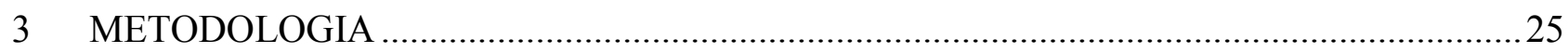

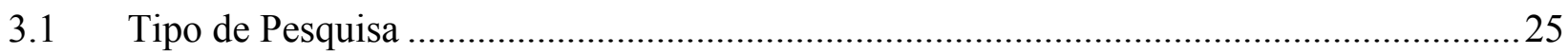

3.2 Participantes da Pesquisa e Amostra de Documentos.....................................................25

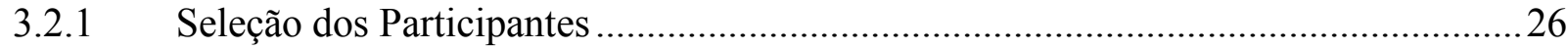

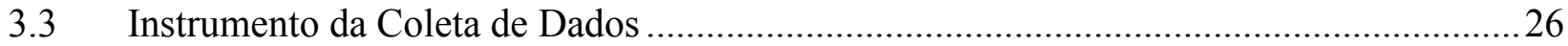

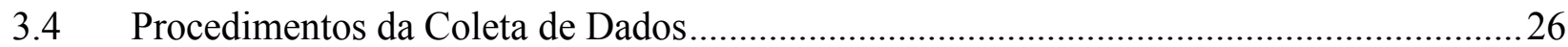

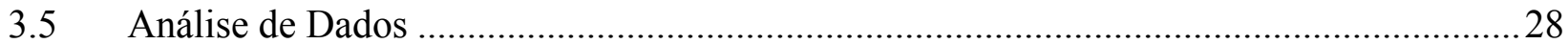

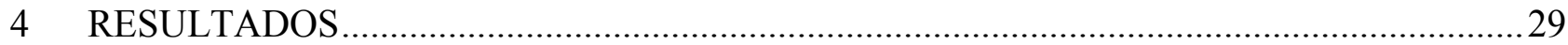

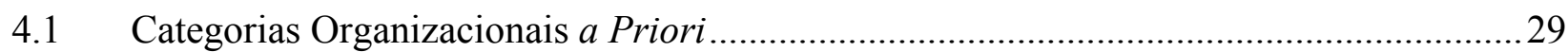

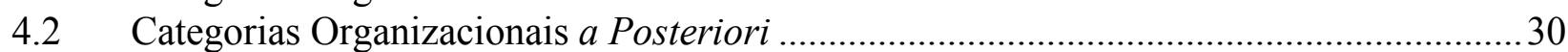

4.3 Resultados e Mapeamento dos Traços Organizacionais do SERPRO ............................... 32

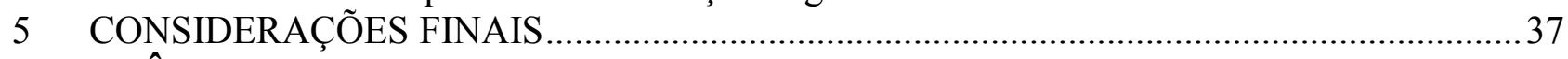

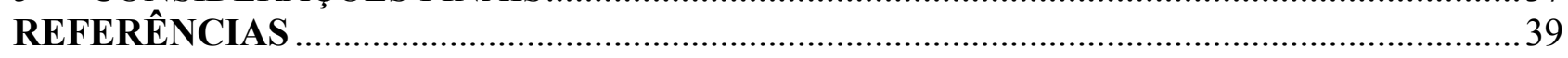




\section{INTRODUÇÃO}

O Serviço Federal de Processamento de Dados (SERPRO) é uma empresa pública, vinculada ao Ministério da Fazenda. Foi criada no dia $1^{\circ}$ de dezembro de 1964, pela Lei ${ }^{\circ} 4.516$, com o objetivo de modernizar e dar agilidade a setores estratégicos da Administração Pública brasileira. A Empresa, cujo negócio é a prestação de serviços em Tecnologia da Informação e Comunicações para o setor público, é considerada uma das maiores Organizações do setor, na América Latina.

O Serpro desenvolve programas e serviços que permitem maior controle e transparência sobre a receita e os gastos públicos, além de facilitar a relação dos cidadãos com o governo.

Ao longo de seus 43 anos, o Serpro consolidou-se como uma referência, aprimorando e desenvolvendo tecnologias utilizadas por órgãos do setor público brasileiro, as quais foram incorporadas à vida dos cidadãos. Atualmente seu corpo técnico conta com aproximadamente 10.000 empregados, qualificados tanto no segmento de TI como nas demais áreas de negócio da empresa.

Por trás desta posição que o SERPRO alcançou perante a sociedade brasileira, certamente há inúmeros elementos tecnológicos, humanos e culturais que assim o permitiram ser. Sua própria história passa por marcos políticos importantes, vindo da ditadura militar até uma política mais liberal. Seu próprio corpo funcional possui uma parcela de empregados que possui mais de 30 anos de casa e que vivenciaram cada uma dessas etapas.

Como a cultura do próprio país mudou ao longo desses aproximados 45 anos, a dinâmica social das pessoas também mudou. $\mathrm{O}$ conjunto de comportamentos e valores considerados válidos transforma-se gradativamente, acompanhando o ritmo do imaginário social e as práticas mais comuns dentro de um contexto organizacional. São esses aspectos, internalizados e reforçados ao longo da história do país e da própria empresa, que a transformam, propiciando melhores ou piores resultados.

Uma organização composta por pessoas, que estão inseridas numa sociedade, tendo papel ativo ou passivo, inevitavelmente terá sua dinâmica organizacional sujeita a algum tipo de influência das facetas da sociedade em que está inserida. É esta influência ou caracterização dela dentro do espaço empresarial que se buscou identificar, bem como os traços da cultura organizacional do SERPRO. 
Vale reforçar que a cultura possuir diversas definições que ilustram como ela pode afetar o contexto organizacional:

Para Castro (2002), a cultura apresenta uma base complexa de valores, padrões, modelos-comuns a uma sociedade, que nos permite identificá-la. Mesmo o Brasil tendo componentes culturais integrados, possui inúmeras variações regionais expressões idiomáticas, vestuário característicos.

- $\quad$ Para Trompenaars (1994) define a cultura como um sistema comum de significados que nos mostra a que devemos prestar atenção, como agir e o que devemos valorizar. Segundo o autor, em razão de cada um de nós levar dentro de si as forma que aprender de organizar as experiências para que estas tenham algum significado, há empregados que trabalham na mesma empresa e por terem culturas diferentes, acabam tendo uma própria visão da empresa diferente da dos demais.

- $\quad$ Para Chiavenato (2004), “cultura é um termo genérico utilizado para significar duas acepções diferentes. De um lado, o conjunto de costumes e realizações de uma época ou de um povo e, de outro lado, artes, erudição e demais manifestações mais sofisticada do intelecto e da sensibilidade humana consideradas coletivamente".

Mesmo diante das diversas definições supracitadas, o foco dessa análise está na identificação do jeito brasileiro "jeitinho", do espírito aventureiro de se planejar e buscar resultados (por vezes insustentáveis a longo prazo), do peso das estruturas hierárquicas (relação chefesubordinado e estrutura organizacional) e da personificação de unidades organizacionais dentro do contexto organizacional do SERPRO.

Este estudo encontra-se estruturado da seguinte forma:

- Esta primeira parte, sendo introdutória e onde é contextualizado o problema e são explicitados os objetivos de sua análise, pesquisa ou solução.

- A segunda parte apresenta o referencial teórico referente à Cultura Nacional e sua influência na Cultura das Organizações Brasileiras;

- A terceira parte apresenta a metodologia empregada para investigação ou mapeamento dos principais traços da cultura organizacional da empresa, baseada principalmente na Análise de Conteúdo (documental e de entrevistas);

- A quarta parte apresenta os resultados da investigação realizada, baseada em categorização dos principais temas organizacionais percebidos sob a ótica dos empregados e coletados a partir de material corporativo. 
- Por fim, é realizada uma conclusão acerca dos resultados obtidos à luz de toda a influência da cultura nacional e dos aspectos principais da cultura organizacional do setor público.

\subsection{Contextualização do problema da pesquisa}

As características e traços culturais de uma organização podem ser fatores de sucesso ou de fracasso, dependendo do cenário organizacional oriundo de aspectos como: comprometimento e satisfação dos colaboradores, modelo de gestão adotado, estilos de liderança, valores da sociedade (e não apenas da organização), cenário sócio-econômico nacional e internacional, entre outros.

Desta forma, parece ser de razoável importância um mapeamento dos valores e práticas (cultura) vivenciados e sustentados no SERPRO, de forma a melhorar o auto-conhecimento organizacional, possibilitando uma melhoria dos resultados corporativos, em todos os seus níveis estratégico, tático, operacional e em suas diversas perspectivas de gestão: financeira, pessoal, empresarial, tecnológica, etc.

O estudo focou em responder a seguinte pergunta: Quais os principais traços da cultura organizacional do SERPRO?

Esta pergunta considera todo o enfoque dado pelo corpo gerencial da empresa, bem como sua Diretoria, na concepção e execução de práticas e programas corporativos de diversas naturezas (tecnológica, financeira, pessoal, empresarial, social, etc), além de também considerar a percepção dos empregados acerca dessas ações corporativas e da dinâmica de trabalho entre todos os colaboradores da empresa, em seus diversos níveis ou tipos de relação.

\subsection{Objetivos}

\subsubsection{Objetivo Geral}

O objetivo geral deste estudo é identificar quais os principais traços da cultura organizacional do SERPRO, a partir de uma abordagem de especialização (do geral para o mais específico) do estudo das culturas relacionadas (nacional e organizacional em geral) à cultura organizacional do SERPRO. 


\subsubsection{Objetivos Específicos}

Especificamente, pretende-se:

- Identificar os principais aspectos da cultura nacional que influenciam o contexto organizacional.

- Identificar os principais aspectos da cultura organizacional que se relacionam com o contexto do SERPRO.

- Identificar os principais traços da cultura organizacional do SERPRO, à luz das principais características do âmbito de Administração no Setor Público Brasileiro. 


\section{REFERENCIAL TEÓRICO}

Esta seção apresenta pontos relacionados à cultura nacional e sua influência no contexto organizacional, baseada na produção científica sobre temas relacionados, fundamentando melhor a pesquisa.

\subsection{Cultura Nacional}

No estudo da cultura das organizações é necessário considerar que as metodologias utilizadas no Brasil, por vezes, baseiam-se em correntes norte-americanas. Porém, segundo Alexandre Borges de Freitas (MOTTA;CALDAS, 1997), precisamos observar os traços da cultura nacional que transcendem à cultura da organização:

\footnotetext{
Ao importarmos metodologias de análise de cultura organizacional, aprendemos como interpretar organizações individuais segundo metodologias que não pressupõem a cultura brasileira como pano de fundo, esquecendo que aspectos importantes da cultura da organização emanam de traços da cultura nacional. (MOTTA;CALDAS, 1997, p. 39)
}

Esses traços citados por Alexandre Borges é que representam aqueles pressupostos básicos que cada individuo usa para enxergar a si mesmo como brasileiro. São características gerais que são comuns à maioria dos brasileiros. O grande desafio é como definir traços nacionais num país que é bastante heterogêneo ou miscigenado.

Há abordagens de estudiosos como Gilberto Freyre (1966) e Caio Prado Jr (1969) que focam sua análise nos aspectos etnológicos e históricos das raízes de nossa cultura. Outro grupo, ao qual Roberto DaMatta (1985) pertence, investe na compreensão dos valores, crenças costume e atitudes presentes em nosso cotidiano social e individual. Ambas as abordagens, apesar de diferenciadas no enfoque, são, em última instância, complementares, e evidenciam a necessidade de se entender, à luz da história da nação, a origem de um perfil comum, segundo Borges (MOTTA;CALDAS, 1997), a "alma nacional".

Nas raízes brasileiras encontraremos principalmente a influência portuguesa, além da indígena e negra, que por fim constituem o chamado "triângulo racial". Em geral, do negro herdamos crenças religiosas, práticas magias e gostos culinários. Do índio herdamos influências nas relações sexuais e familiares, na magia e na mítica. Mesmo considerando que ainda assimilamos culturas imigrantes diversas (italianos, alemães, sírios, libaneses, judeus, japoneses, coreanos, etc.) são nas raízes lusitanas que se encontram os nossos principais traços brasileiros. 
Portugal foi um país que se formou entre a África e a Europa. Situado numa localização que propiciou o contato com vários povos e culturas, desenvolveu-se a partir de intensa circulação de raças das mais diversas procedências. Por muito tempo permaneceu em estado de guerra, sendo invadido por diversos povos. Esse estado de conquista e reconquista, com fluxo acentuado de diferentes raças impossibilitou o estabelecimento de uma hegemonia de raça, seja de cultura, seja de classe social. Inclusive, este cenário favoreceu a grande mobilidade social no poder, onde nem mesmo a nobreza, conseguiu formar uma aristocracia fechada, ao inverso do que ocorreu em boa parte da Europa. Portugal sofreu a carga da influencia de diversas raças, nos aspectos sexuais, alimentação e religiosos, onde até mesmo a rigidez doutrinária e moral da Igreja Medieval, do Cristianismo, da discipline canônica, do latim e da arquitetura gótica foi abalada

Com base nesse caráter português, de plasticidade, flexibilidade, antagonismos e contrastes, que ocorreu a formação da sociedade brasileira, durante e após sua colonização. E é a partir desse cenário que Borges resgata traços característicos de nossa "alma nacional” e apresenta os principais deles que afetam uma análise organizacional:

\begin{tabular}{|c|c|}
\hline Traço & Características-Chave \\
\hline 1. Hierarquia & $\begin{array}{l}\text { - Tendência a centralização do poder } \\
\text { dentro dos grupos sociais } \\
\text { - Distanciamento nas relações entre } \\
\text { diferentes grupos sociais } \\
\text { - Passividade e aceitação dos grupos } \\
\text { inferiores }\end{array}$ \\
\hline 2. Personalismo & $\begin{array}{l}\text { - Sociedade baseada em relações pessoais } \\
\text { - Busca de proximidade e afeto nas } \\
\text { relações } \\
\text { - Paternalismo: domínio moral e } \\
\text { econômico }\end{array}$ \\
\hline 3. Malandragem & $\begin{array}{l}\text { - Flexibilidade e adaptabilidade como } \\
\text { meio de navegação social } \\
\text { - Jeitinho }\end{array}$ \\
\hline 4. Sensualismo & $\begin{array}{l}\text { - Gosto pelo sensual e pelo exótico nas } \\
\text { relações sociais }\end{array}$ \\
\hline
\end{tabular}




\begin{tabular}{|l|l|}
\hline 5. Aventureiro & $\begin{array}{l}\text { - } \\
\text { - }\end{array}$ \\
& $\begin{array}{l}\text { Tendência à aversão ao trabalho manual } \\
\text { ou metódico }\end{array}$ \\
\hline
\end{tabular}

Quadro 1 - Traços Brasileiros e Características-chave

Fonte: (MOTTA;CALDAS, 1997, p.44)

\subsection{Cultura Organizacional}

Definir cultura organizacional não há algo trivial, devido a grande variação entre as percepções das pessoas sobre o assunto, porém, segundo um consenso apontado por Robbins (ROBBINS, 2005), a Cultura Organizacional pode ser entendida como um sistema de valores compartilhado pelos membros que diferencia uma organização das demais. Onde esse sistema é um conjunto de características-chave que a organização valoriza. Segundo Robbins (2005), entre as características principais que capturam a essência da cultura de uma organização são apresentadas na tabela a seguir:

\begin{tabular}{|c|c|}
\hline Características & Descrição \\
\hline Inovação e assunção de riscos & $\begin{array}{l}\text { O grau em que os funcionários são estimulados } \\
\text { a inovar e a assumir riscos }\end{array}$ \\
\hline Atenção aos Detalhes & $\begin{array}{l}\text { O grau em que se espera que os funcionários } \\
\text { demonstre precisão, análise e atenção aos } \\
\text { detalhes. }\end{array}$ \\
\hline Orientação para os resultados & $\begin{array}{l}\text { O grau em que os dirigentes gocam mais os } \\
\text { resultados do que as técnicas e os processos } \\
\text { empregado para o seu alcance }\end{array}$ \\
\hline Orientação para as pessoas & $\begin{array}{l}\text { O grau em que as decisões dos dirigentes levam } \\
\text { em consideração o efeito dos resultados sobre as } \\
\text { pessoas dentro da organização }\end{array}$ \\
\hline Orientação para a equipe & $\begin{array}{l}\text { O grau em que as atividades de trabalho são } \\
\text { mais organizadas em termos de equipes do que } \\
\text { de indivíduos }\end{array}$ \\
\hline Agressividade & $\begin{array}{l}\text { O grau em que as pessoas são competitivas e a } \\
\text { agressiva, em vês de dóceis e acomodadas }\end{array}$ \\
\hline Estabilidade & O grau em que as atividades organizacionais \\
\hline
\end{tabular}


enfatizam a manutenção do status quo em

contraste com o crescimento

Quadro 2 - Principais Características da Cultura Organizacional

Fonte: (ROBBINS, 2005, p.375)

A cultura de uma organização tem papel fundamental no comportamento dos funcionários e parece ganhar importância cada vez maior no atual ambiente de trabalho (ROBBINS, 2005). Graças a um "achatamento" de estrutura, onde surgem em maior destaque o trabalho em equipe, a redução da formalização e maior autonomia aos funcionários, há um compartilhamento maior dos valores entre os funcionários e por fim, uma maior identidade cultural da empresa perante as demais, baseada nas características supracitadas.

Daí a importância de se entender quais, como e em que nível esses valores organizacionais são compartilhados, uma vez que, inevitavelmente, parte desses valores se entrelaça ou tem origem nos valores da sociedade em que a organização está inserida. A partir desta perspectiva, pode-se melhor mapear a influência externa à organização, a da cultura nacional.

\subsection{A relação entre Cultura Nacional e Cultura Organizacional}

A vivência corporativa, num contexto de crise das instituições tradicionais, como definido por Freitas (2002), onde o que prevalece (inclusive no setor público) é a manutenção de uma fonte de renda, progressão e status, por vezes gera ao indivíduo, um cenário de alienação e falta de percepção crítica da própria essência da organização.

Essa perda de percepção organizacional permite que tanto os líderes como seus liderados mergulhem numa dinâmica de trabalho onde o fim da atividade não é mais relacionado aos resultados próprios de sua execução, mas sim, aquilo que se consegue em benefício próprio a partir dela.

Neste contexto, um "hábito" organizacional se cria, se sustenta e se propaga ao longo da geração de seus colaboradores sem que nele seja aplicado um olhar crítico, sob o aspecto humano, social e cultural, acerca do que o efetivamente faz ou fez com que esse hábito fosse como tal, e se propagasse por tanto tempo. É importante consideramos a essência da imutabilidade ou variabilidade comportamental em organizações sob a perspectiva da cultura nacional. 
Segundo pesquisas apontadas por Robbins (2005), que defende que as diferenças nacionais devem ser levadas em consideração numa previsibilidade de maior precisão sobre o comportamento organizacional, a cultura nacional ainda tem um impacto maior sobre os funcionários do que a cultura organizacional. Por exemplo, os funcionários da IBM em Munique são mais influenciados pela cultura alemã do que pela cultura organizacional da IBM, que mesmo sendo uma multinacional zeladora de elevado padrão de qualidade e perfil profissional, não consegue superar as raízes mais profundas do indivíduo, enraizadas na sua origem social.

Desta forma, considera-se muito importante uma definição mais precisa da fronteira de influência entre a cultura nacional e a cultura organizacional, uma vez que é nessa fronteira que se consegue respeitar o comportamento do indivíduo baseado nas raízes de sua sociedade e ainda internalizar a cultura organizacional da empresa que precisa se destacar perante suas concorrentes e firmar sua própria identidade perante a sociedade em que está inserida.

\subsection{A influência da Cultura Nacional nas organizações}

A cultura é representada por um conjunto de comportamentos executados por grupos sociais, que evidenciam sua maneira de pensar, seu senso ético e até senso crítico. É este conjunto que orienta, mesmo que inconscientemente, o dia-a-dia das pessoas no trabalho, na comunidade e na família. A cultura é consolidada durante determinado período e também revisada ou interferida por novos fatores que até ela são levados, principalmente, num mundo cada vez mais globalizado.

Toda dinâmica social pode ser influenciada na medida em que se conhece como ela funciona e como se supera padrões raramente questionados. Neste sentido, a cultura é baseada em modelos mentais e está sujeita a uma contínua transformação, mesmo que ainda morosa.

Para Motta e Caldas (1997), a cultura é um complexo coletivo feito de "representações mentais" que ligam o imaterial e o material, a infra-estrutura e as superestruturas. Um movimento dialético inevitável entre o que chamamos de material, ou seja, as estruturas econômicas, as técnicas, as estruturas sociais, as leis e normas, as vivências concretas, e o que denominamos de imaterial, no qual se encontram a vida simbólica e suas representações, ideologias e idéias.

Esse mundo imaterial, onde estão o conjunto de valores, crenças e símbolos que influenciam o comportamento do individuo diante de sua família, de seu trabalho e de sua organização, é gerado, alimentado e sustentado por elementos materiais. É evidente que as representações e a simbologia de nosso cotidiano são suportados e só existem à medida que nascem de um fato concreto das estruturas sociais, das experiências vividas, do mundo material. (MOTTA;CALDAS, 1997, p. 40-41) 
Portanto, é interessante que se conheça a fundo os valores da cultura de um determinado grupo, de forma a que possa melhor influenciá-lo a determinadas ações, a partir da vinculação entre o comportamento e o sentido, entre o símbolo e o significado.

São esses traços que por vezes podem ser materializados na própria missão das organizações, reestruturando-as e gerando contínuos processos de readaptação.

\subsection{Aspectos da Cultura Organizacional do Serviço Público}

Com base no conteúdo supracitado nos itens anteriores, há de superar alguns preceitos culturais internalizados na cultura organizacional do serviço público, como o comodismo, protecionismo e corporativismo, bem como a estabilidade.

Há uma necessidade de modernização das organizações, onde, de acordo com Freitas (2002, p. 55), "as organizações modernas são produtos da história e do tempo das sociedades onde se inserem, bem como da evolução dessas sociedades. Se hoje elas têm papel cada vez mais importante no cenário social é porque o próprio social lhes abre espaço. E quando as organizações tentam criar um imaginário próprio é ainda no social que elas vão encontrar as mensagens que tenham significados para seus públicos específicos”.

Este cenário ainda é um pouco distante de nossa realidade, onde há o histórico de colonização do país, quando se utilizou o poder para privilegiar uma minoria (que possuía maior renda) em detrimento de uma maioria marginalizada.

Ainda hoje, de acordo Johann (2004), a própria palavra corporação suscita imagem de autoridade e burocracia. O termo também evoca imagens de máquinas, em que prevalece a cadeia de comando entrelaçada por superiores dirigindo subordinados. Além disso, de acordo com Motta e Caldas (1997, p.31), “as organizações brasileiras geralmente apresentam uma distância de poder tão grande que parecem lembrar a distribuição de renda nacional e o passado escravocrata".

Este passado ainda manifesta-se nas estruturas organizacionais brasileiras, onde ainda se considera que apenas um controle rígido dos seus empregados é que propiciará resultados adequados, esquecendo-se de aspectos humanos que podem comprometer a motivação do individuo.

No estudo das organizações, a cultura equivale ao modo de vida da organização em todos os seus aspectos como idéias, crenças, costumes, regras, etc. Neste sentido, a cultura representa o universo simbólico da organização e proporciona um referencial de padrão de desempenho entre os funcionários, influenciando a pontualidade, produtividade e a preocupação com a qualidade e 
serviço ao cliente. Ela é construída ao longo do tempo e passa a impregnar todas as práticas, construindo um complexo de representações mentais e um sistema coerente de significados que une todos os membros em torno dos mesmos objetivos e do mesmo modo de agir (CHIAVENATO, 2004).

A partir disso, um estudo sobre os traços principais da cultura organizacional de uma empresa podem levar a uma potencialização de resultados, uma vez que a própria organização passar a se conhecer melhor, podendo superar paradigmas e reforçar práticas de sucesso, evidenciadas pela sua história.

\subsection{O estilo brasileiro de administrar}

Muitos estudos têm sido realizados com o intuito de pensar a cultura brasileira na gestão empesarial, entre eles, temos o estudo de Marco Aurélio Spyer Prates e Betânia Tanure de Barros (MOTTA;CALDAS,1997), que propõem o chamado Sistema de Ação Cultural Brasileiro, que mapeia os principais traços culturais presentes na empresa brasileira.

O trabalho é baseado na percepção de 2.500 dirigentes e gerentes de 520 empresas de grande e médio porte do Sudoeste e São Paulo e aliado a outros estudos da cultura brasileira, baseados em Roberto DaMatta e Barbosa:

O sistema proposto é composto por quatro subsistemas: o institucional (ou formal) e o pessoal (ou informal), o dos líderes e dos liderados, que apresentação traços culturais em comum e traços especiais, que articulam o conjunto como um todo (MOTTA;CALDAS,1997). A contínua e variável sobreposição desses fatos, em maior ou menor intensidade, dependendo de cada contexto empresarial, acaba por gerar interseções entre os subsistemas:

- Concentração de poder na interseção dos subsistemas líderes e formal;

- Postura de espectador na interseção dos subsistemas liderados e formal;

- Personalismo de poder na interseção dos subsistemas líderes e pessoal;

- Evitar Conflito na interseção dos subsistemas líderes e formal;

Além disso, os subsistemas estão articulados também por meio de traços especiais que acabam sendo responsáveis pela não-ruptura de todo o sistema. São eles que quando alterados em grau ou natureza podem gerar uma mudança efetiva organizacional. Esses traços são: $o$ paternalismo, a lealdade às pessoas, o formalismo e a flexibilidade. A figura a seguir ilustra a estrutura do Sistema criado com base em todos esses traços. 


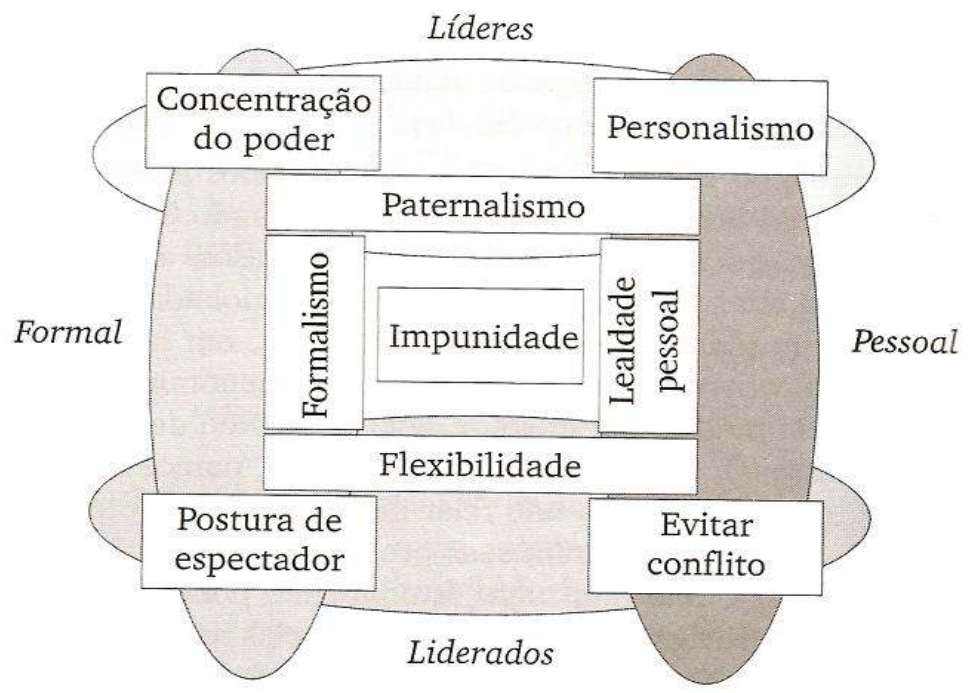

Figura 1 - Visão integrada do sistema de ação cultural brasileiro (modelo proposto)

Para uma melhor compreensão de todos esses traços, é apresentado um quadro sumário desses traços e suas descrições.

\begin{tabular}{|c|c|c|}
\hline Subsistemas & Traços & Descrição \\
\hline \multirow{3}{*}{ Líderes } & $\begin{array}{c}\text { Concentração de } \\
\text { Poder }\end{array}$ & $\begin{array}{l}\text { Baseada na hierarquia/subordinação, historicamente } \\
\text { sustentada pela força militar e pelo poder racional-legal. } \\
\text { Culturalmente se sustenta a partir de pensamentos como } \\
\text { "Manda quem pode, obedece quem tem juízo" }\end{array}$ \\
\hline & Personalismo & $\begin{array}{l}\text { A pessoa está acima da instituição, não havendo } \\
\text { homogeneidade no tratamento ao cidadão, variando } \\
\text { conforme a pessoa e seu carisma }\end{array}$ \\
\hline & Paternalismo & $\begin{array}{l}\text { Surge pela combinação da Concentração de Poder e } \\
\text { Personalismo, onde tanto liderados e líderes apresentam } \\
\text { dependência mútua, um no sentido de ser acolhido por } \\
\text { um "pai", o outro, no sentido de ter que "acolher" e } \\
\text { controlar seus subordinados }\end{array}$ \\
\hline Institucional & $\begin{array}{l}\text { Postura de } \\
\text { Espectador }\end{array}$ & $\begin{array}{l}\text { É caracterizado pelo Mutismo e baixo senso crítico, } \\
\text { historicamente desenvolvido pela nossa tradição de } \\
\text { mandonismo e paternalismo. }\end{array}$ \\
\hline
\end{tabular}




\begin{tabular}{|c|c|l|}
\hline \multirow{2}{*}{ Formalismo } & $\begin{array}{l}\text { Caracterizado pela rigidez das normas ao nível de teoria } \\
\text { e pela contínua tentativa de vencê-las, ao nível de } \\
\text { prática ("fazer vista grossa") }\end{array}$ \\
\cline { 2 - 4 } & Impunidade & $\begin{array}{l}\text { Caracterizado pela luta para se permanecer no poder, } \\
\text { onde líderes tentam se isentar das punições }\end{array}$ \\
\hline \multirow{2}{*}{ Pessoal } & Lealdade Pessoal & $\begin{array}{l}\text { Maior valorização aos membros de um grupo específico } \\
\text { do que a um sistema maior no qual está inserido }\end{array}$ \\
\cline { 2 - 4 } & Flexibilidade Conflito & $\begin{array}{l}\text { Resolução de conflitos por meio de "triangulações", } \\
\text { mediadores de bom relacionamento interpessoal, o que } \\
\text { acaba reforçando a "Lealdade Pessoal" }\end{array}$ \\
\hline \multirow{2}{*}{ Liderados } & $\begin{array}{l}\text { Caracterizada pela adaptabilidade a situações adversas e } \\
\text { criatividade para resolvê-las }\end{array}$ \\
\hline
\end{tabular}

Quadro 3 - Visão sumária dos traços do Sistema de Ação Cultural Brasileiro

A tabela a seguir ilustra os resultados obtidos na percepção de diversos dirigentes e gerentes de empresas da grande e médio porte, conforme supracitado no começo deste tópico, acerca do modelo proposto para o Sistema de Ação Cultural Brasileiro.

Tabela 1 - Principais Traços culturais presentes na empresa brasileira

\begin{tabular}{|c|c|c|}
\hline Características & $\begin{array}{c}\text { Concordam e Concordam em } \\
\text { Parte (\%) }\end{array}$ & $\begin{array}{c}\text { Discordam e Discordam em } \\
\text { Parte (\%) }\end{array}$ \\
\hline Concentração de Poder & 88 & 12 \\
\hline Flexibilidade & 81 & 19 \\
\hline Paternalismo & 77 & 23 \\
\hline Dependência & 76 & 24 \\
\hline Lealdade às pessoas & 71 & 31 \\
\hline Personalismo & 69 & 31 \\
\hline Impunidade & 69 & 32 \\
\hline Evitar Conflito & 68 & 33 \\
\hline Postura de espectador & 67 & 35 \\
\hline Formalismo & 65 & \\
\hline
\end{tabular}

Fonte: (MOTTA;CALDAS, 1997, p.68)

O modelo proposto por Marco Aurélio e Batenia Tanure, com um bom nível de aprovação, conforme tabela supracitada, estrutura o estilo brasileiro de administrar em diversos tipos de 
subsistemas, demonstrando como se inter-relacionam e se interpõem os principais traços da cultura brasileira, criando um resultado único e original: o estilo brasileiro de administrar. 


\section{METODOLOGIA}

Nesta seção é descrita a metodologia de pesquisa adotada no mapeamento dos traços da cultura organizacional do SERPRO, à luz de elementos da cultura nacional brasileira e da própria história do SERPRO.

O objetivo da metodologia de pesquisa é apresentar conceitos sobre a amostra e seleção dos sujeitos envolvidos na pesquisa, os objetos e mecanismos relacionados ao processo científico de desenvolvimento da pesquisa (VERGARA, 2000).

\subsection{Tipo de Pesquisa}

Trata-se de uma pesquisa qualitativa e descritiva, baseada nos conceitos apresentados por Vergara (2000).

Quanto aos meios, a pesquisa será bibliográfica, documental e de campo. Bibliográfica porque a fundamentação do trabalho é baseada em material científico produzido. Documental porque contará com o levantamento de documentação corporativa, como, por exemplo: regimento interno, normas, decisões de diretoria, comunicados internos, etc. Por fim, a pesquisa também é de campo, porque coleta dados a partir da aplicação de entrevistas com colaboradores do quadro próprio da empresa.

Quanto aos fins, a pesquisa é descritiva e aplicada. Descritiva porque caracteriza o cenário organizacional a partir da percepção de seus colaboradores e Aplicada porque subsidia um melhor autoconhecimento corporativo, potencializando a resolução de problemas empresariais.

\subsection{Participantes da Pesquisa e Amostra de Documentos}

A pesquisa foi baseada na entrevista de dezoito funcionários, distribuídas em 3 grupos focais de seis participantes cada, incluindo servidores de nível fundamental, médio e de superior do quadro efetivo da organização, lotados na sede da empresa, em Brasília - DF, ou nas diversas extensões regionais da empresa, ao longo do território nacional.

A amostra de documentos foi baseada documentação corporativa, como normas, decisões de diretoria, etc. 


\subsubsection{Seleção dos Participantes}

Os sujeitos da pesquisa foram os servidores efetivos da empresa, dado o seu vínculo mais forte com a empresa e seu relacionamento direto com as atividades principais da empresa (diferente de boa parte de terceirizados que atuam na área de apoio, como segurança, serviços gerais, etc.).

\subsection{Instrumento da Coleta de Dados}

O mapeamento dos traços da cultura organizacional do SERPRO ocorreu a partir de duas fontes: entrevistas com grupos focais, baseada em roteiro semi-estruturado e coleta de material corporativo, com a devida autorização da chefia imediata do pesquisador.

Como base para elaboração do roteiro semi-estruturado da entrevista, foram realizados contatos prévios com empregados mais antigos na empresa, de forma a poder se observar mais tópicos e assuntos referentes ao contexto da empresa. Não obstante, também foram ouvidos empregados mais novos, que podem trazer para pauta um olhar mais crítico (menos viciado) da empresa, até mesmo por influência de outras organizações em que trabalharam recentemente. Por fim, também foram consultados funcionários que estavam cedidos a outros órgãos do Governo e apenas recentemente passaram a trabalhar no SERPRO efetivamente, trazendo uma perspectiva externa (e até mesmo de cliente, uma vez que também era atendido pelo SERPRO) crítica e rica para a preparação de temas-chaves na entrevista.

Como base para a coleta de documentos corporativos, foi utilizado o próprio portal de conteúdo da empresa, onde são armazenados normas, decisões e processos empresariais, além de referência a outros sistemas de informação relacionados e a sítios das diversas unidades da empresa.

\subsection{Procedimentos da Coleta de Dados}

O procedimento para coleta de dados, seja por meio de material corporativo ou entrevista, foi subsidiado por autorização da própria universidade corporativa da empresa, uma vez que o trabalho não tem propósito efetivamente externo, e sim, interno, uma vez que propicia um autoconhecimento organizacional bem como oportunidades de melhoria.

Devido a inviabilidade de se reunir todas as pessoas dos grupos em momentos ou horários específicos, optou-se pela distribuição do questionário da entrevista a cada um dos participantes. Foi realizado um contato verbal com cada um deles a fim de lhes explicar a estrutura do questionário bem como assegurar-lhes sobre a preservação de sua identidade, uma vez que o foco 
da entrevista não é identificar ou qualificar uma pessoa, mas sim, o individuo dentro da organização e sua percepção sobre ela. Em alguns casos, as respostas dos entrevistados foram melhor esclarecidas de forma verbal (e não escrita), propiciando ao pesquisador (entrevistador) uma liberdade maior para ouvir e prestar toda a sua atenção ao discurso do entrevistado (LÜDKE, 1986, p. $37)$.

Os dados básicos coletados dos entrevistados foram sua história profissional, seu perfil funcional atual, tempo de serviço na empresa e localidade.

Em relação à pesquisa documental, a base foi o material existente no portal corporativo da empresa.

A seguir, segue o quadro de perguntas da entrevista:

\begin{tabular}{|c|c|}
\hline Questão & Descrição \\
\hline 01 & $\begin{array}{l}\text { Você entende que há alinhamento entre o perfil dos empregados e os valores } \\
\text { organizacionais do SERPRO? Caso não, em que contexto, situação ou } \\
\text { proporção ele ocorre? }\end{array}$ \\
\hline 02 & $\begin{array}{l}\text { Na sua visão, quais as melhores áreas ou programas de nível corporativo (ex: } \\
\text { responsabilidade social, gestão de pessoas, gestão financeira, metodologias, } \\
\text { etc.) executados pelo SERPRO? }\end{array}$ \\
\hline 03 & $\begin{array}{l}\text { Na sua visão, quais as áreas ou programas de nível corporativo (ex: } \\
\text { responsabilidade social, gestão de pessoas, gestão financeira, metodologias, } \\
\text { tecnologia, etc.) que mais necessitam de melhoria no SERPRO? }\end{array}$ \\
\hline 04 & $\begin{array}{l}\text { Na sua visão, como se dá a relação entre chefe e subordinado no SERPRO? } \\
\text { Favor explicar no caso de considerá-lo adequado ou inadequado. }\end{array}$ \\
\hline 05 & $\begin{array}{l}\text { Na sua visão, como se dá a relação entre Empregados, Sindicato e Diretoria do } \\
\text { SERPRO? (Considerar a relação dentro e fora das negociações de ACT) }\end{array}$ \\
\hline 06 & $\begin{array}{l}\text { Na sua visão, como se dá o alinhamento ou influência política no SERPRO? } \\
\text { Favorece ou prejudica? Em que ocasiões? }\end{array}$ \\
\hline 07 & $\begin{array}{l}\text { Na sua visão, como se dá o processo de progressão funcional e desempenho do } \\
\text { empregado no SERPRO? Favor explicar no caso de considerá-lo adequado ou } \\
\text { inadequado. }\end{array}$ \\
\hline 08 & $\begin{array}{l}\text { Na sua visão, qual a relação entre o perfil do empregado do SERPRO (ex: } \\
\text { comprometido, desmotivado, inovador, etc.) e o perfil do servidor público? Em } \\
\text { que ocasiões normalmente há variações? }\end{array}$ \\
\hline 09 & $\begin{array}{l}\text { Quais as características do SERPRO que você aprecia e que devem continuar } \\
\text { sendo praticadas e valorizadas? }\end{array}$ \\
\hline 10 & $\begin{array}{l}\text { Quais as características do SERPRO que você entende que precisam ser } \\
\text { aperfeiçoadas com urgência? }\end{array}$ \\
\hline
\end{tabular}

Quadro 4 - Questionário da Entrevista 
$\mathrm{Na}$ entrevista buscou-se abordar temas como relação chefia-subordinado, influência política, processos e programas corporativos, desempenho e evolução funcional, possibilitando a análise de conteúdo com um enfoque em algumas das características apresentadas no capítulo de referencial teórico, como por exemplo, ritos formais, posturas paternais e o estilo brasileiro de administrar.

\subsection{Análise de Dados}

A análise de dados foi realizada, considerando abordagem já praticada por Puglisi e Franco (2003), onde se utiliza um modelo híbrido de categorização: a categorização a priori e a categorização a posteriori. Desta forma, são criadas categorias de conteúdo iniciais (moleculares) de menor amplitude e ao longo da análise do conteúdo das entrevistas, essas categorias poderão ser agrupadas em novas categorias com semântica de maior amplitude (molares), permitindo a integração e unificação de diversos pontos comuns abordados pelos entrevistados, mas sob formas diferentes.

Por fim, a documentação levantada também foi categorizada e em seguida, realizou um cruzamento entre as categorias de documentação produzida e as categorias mapeadas nas entrevistas, a partir da percepção dos próprios empregados, buscando-se verificar o nível de convergência entre os dois mundos e gerar um mapeamento rico e consistente (não-unilateral) dos traços da cultura da empresa. 


\section{RESULTADOS}

Este capítulo reúne os resultados auferidos a partir de entrevistas individuais com profissionais das organizações selecionadas, bem como da análise de documentos internos. Desta forma, são refletidas as percepções dos indivíduos entrevistados em conjunto com as práticas corporativas de direcionamento estratégico (diretoria) sob à luz do arcabouço teórico referente à Cultura Nacional e Cultura Organizacional.

\subsection{Categorias Organizacionais a Priori}

$\mathrm{O}$ quadro a seguir apresenta as categorias organizacionais mapeadas a partir do portal corporativo da empresa (http://serpronet.serpro). Elas foram agrupadas com base nos principais assuntos abordados em apresentações para o corpo gerencial e nos programas corporativos patrocinados pela empresa.

\begin{tabular}{|c|c|c|}
\hline \multicolumn{2}{|c|}{ Lista de Categorias de Conteúdo do Contexto Organizacional do SERPRO } \\
\cline { 1 - 2 } Tipo de Categorização: & A Priori & \\
\cline { 1 - 2 } Origem da Categorização: & $\begin{array}{c}\text { Material } \\
\text { Corporativo }\end{array}$ & \\
\cline { 1 - 2 } Tipo de Percepção: & Empresa & \multirow{2}{*}{ Evidências } \\
\hline Processos Corporativos & $\begin{array}{l}\text { Processo de Desenvolvimento de Sistemas, } \\
\text { Gestão de TI e Gerenciamento de Projetos }\end{array}$ \\
\hline Planejamento Estratégico & $\begin{array}{l}\text { Planejamento Estratégico Situacional (em } \\
\text { níveis setoriais, inclusive) }\end{array}$ \\
\hline Gestão Empresarial & $\begin{array}{l}\text { Política Comercial e Portfólio de Projetos e } \\
\text { Unidade de Auditoria }\end{array}$ \\
\hline Gestão Financeira e Contratual & Política de Preços e Gestão Contratual \\
\hline Gestão de Negócios & $\begin{array}{l}\text { Preparação de Cursos para Analistas de } \\
\text { Negócio e Modelagem de Negócios }\end{array}$ \\
\hline Gestão de Serviços & $\begin{array}{l}\text { Diversos níveis de atendimento estruturados, } \\
\text { com comunidades de atendimento e } \\
\text { ferramentas }\end{array}$ \\
\hline
\end{tabular}




\begin{tabular}{|c|l|}
\hline Gestão de Projetos & $\begin{array}{l}\text { Processo Corporativo de Gerenciamento de } \\
\text { Projetos }\end{array}$ \\
\hline $\begin{array}{c}\text { Gestão de Infra-Estrutura (Parque Computacional e } \\
\text { Rede) }\end{array}$ & $\begin{array}{l}\text { Processo de Desenvolvimento de Sistemas, } \\
\text { Gestão de TI e Gerenciamento de Projetos }\end{array}$ \\
\hline Gestão de Pessoas & $\begin{array}{l}\text { Novo Plano de Cargos e Salarios e Nova } \\
\text { Metodologia de Avaliação Funcional }\end{array}$ \\
\hline Responsabilidade Social & $\begin{array}{l}\text { Processo de Responsabilidade Social e } \\
\text { Inclusão digital }\end{array}$ \\
\hline Comunicação Social e Empresarial & $\begin{array}{l}\text { Informes empresariais e sociais e reuniões com } \\
\text { corpo gerencial }\end{array}$ \\
\hline Desenvolvimento Pessoal & $\begin{array}{l}\text { Programa GDES (Gerenciamento do } \\
\text { Desempenho) e FCT (Gratificação por } \\
\text { Desempenho) }\end{array}$ \\
\hline Desenvolvimento Gerencial & Programas de Formação Gerencial \\
\hline Marketing & Existência de Unidade Específica \\
\hline Missão Corporativa & Existência de Valores Corporativos \\
\hline Gestão de Tecnologia & Existência de Unidade Específica \\
\hline
\end{tabular}

Quadro 5 - Categorias Organizacionais a priori

\subsection{Categorias Organizacionais a Posteriori}

O quadro a seguir apresenta as categorias organizacionais mapeadas a partir das entrevistas realizadas com os funcionários da empresa. As categorias moleculares foram agrupadas em níveis maiores (molares) de forma a possibilitar uma comparação entre a visão empresarial e a visão dos empregados.

\begin{tabular}{|c|c|c|}
\hline \multicolumn{3}{|c|}{ Mapeamento Categorias Principais x Entrevistas } \\
\hline Agrupamento das Categorias & $\begin{array}{c}\text { Categorias } \\
\text { Identificadas ao } \\
\text { longo da entrevista }\end{array}$ & $\begin{array}{l}\text { Nível de } \\
\text { Percepção }\end{array}$ \\
\hline \multirow{3}{*}{ Integração das unidades } & $\begin{array}{c}\text { Alinhamento } \\
\text { Estratégico em } \\
\text { vários níveis }\end{array}$ & Baixo \\
\hline & $\begin{array}{c}\text { Orientação } \\
\text { Empresarial e } \\
\text { Comercial }\end{array}$ & Medio \\
\hline & Feudos Internos & Alto \\
\hline \multirow{4}{*}{ Processos Corporativos } & $\begin{array}{c}\text { Metodologias e } \\
\text { Processos }\end{array}$ & Excelente \\
\hline & Burocracia & Alta \\
\hline & Foco em Utilidade & Medio \\
\hline & - & - \\
\hline
\end{tabular}




\begin{tabular}{|c|c|c|}
\hline \multirow{4}{*}{ Gestão Empresarial } & Gestao Financeira & Medio \\
\hline & Gestao Pessoas & Baixo \\
\hline & Gestão de Negócios & Medio \\
\hline & Visibilidade & Baixo \\
\hline \multirow{4}{*}{ Relação Trabalhista } & $\begin{array}{c}\text { Transparência } \\
\text { Diretoria }\end{array}$ & Media \\
\hline & $\begin{array}{l}\text { Transparência } \\
\text { Sindicato }\end{array}$ & Media \\
\hline & Interesses Políticos & Alto \\
\hline & $\begin{array}{l}\text { Confiabilidade no } \\
\text { Processo de } A C T\end{array}$ & Baixa \\
\hline \multirow{3}{*}{ Satisfação no Trabalho } & $\begin{array}{l}\text { Relação Amigável } \\
\text { entre funcionarios }\end{array}$ & Alta \\
\hline & $\begin{array}{c}\text { Salário compativel } \\
\text { com o nível do } \\
\text { profissional } \\
\end{array}$ & Baixo \\
\hline & $\begin{array}{c}\text { Bom Ambiente de } \\
\text { Trabalho }\end{array}$ & Alto \\
\hline \multirow{4}{*}{ Lideranças/Desenv.Gerencial } & Perfil Técnico & Medio \\
\hline & $\begin{array}{c}\text { Influência por } \\
\text { Amizade }\end{array}$ & Alto \\
\hline & Influência Política & Medio \\
\hline & $\begin{array}{c}\text { Evolução Funcional ( } \\
\text { Técnico Compativel } \\
\text { com Gerencial) - } \\
\text { Carreira em Y } \\
\end{array}$ & Baixo \\
\hline \multirow{4}{*}{ Desenvolvimento Pessoal } & Motivação & Medio \\
\hline & Comprometimento & Medio \\
\hline & Inovação & Alto \\
\hline & Evolução Funcional & Baixo \\
\hline \multirow[t]{2}{*}{ Política Comercial } & $\begin{array}{c}\text { Orientação } \\
\text { Empresarial }\end{array}$ & Medio \\
\hline & Fronteira de Atuação & Medio \\
\hline \multirow{4}{*}{$\begin{array}{c}\text { Comunicação Social e } \\
\text { Empresarial }\end{array}$} & $\begin{array}{c}\text { Orientação } \\
\text { Empresarial }\end{array}$ & Medio \\
\hline & Verticalização & Medio \\
\hline & Grau de Divulgação & Medio \\
\hline & Eficiência & Medio \\
\hline \multirow{4}{*}{ Foco no Resultado } & $\begin{array}{c}\text { Burocracia no } \\
\text { Processo } \\
\end{array}$ & Medio \\
\hline & Prazos Inviaveis & Medio \\
\hline & Foco no Cliente & Medio \\
\hline & Respostas Rapidas & Baixo \\
\hline
\end{tabular}

Quadro 6 - Categorias Organizacionais a posteriori 


\subsection{Resultados e Mapeamento dos Traços Organizacionais do SERPRO}

\begin{tabular}{|c|c|c|c|c|c|c|c|}
\hline \multicolumn{8}{|c|}{ Mapeamento dos Traços Organizacionais do SERPRO } \\
\hline $\begin{array}{c}\text { Categorias Organizacionais } \\
\text { (Visão Empresa) }\end{array}$ & $\begin{array}{l}\text { Categorias Organizacionais } \\
\text { (Visão Empregado) }\end{array}$ & $\begin{array}{c}\text { Desapercebido pelo } \\
\text { empregado }\end{array}$ & $\begin{array}{c}\text { Identificado com } \\
\text { destaque pelo } \\
\text { empregado }\end{array}$ & $\begin{array}{c}\text { Nível de } \\
\text { Percepção do } \\
\text { Empregado }\end{array}$ & $\begin{array}{c}\text { Tipo de } \\
\text { Percepção do } \\
\text { Empregado }\end{array}$ & $\begin{array}{c}\text { Traços da } \\
\text { Cultura } \\
\text { Nacional }\end{array}$ & $\begin{array}{c}\text { Traços da Cultura } \\
\text { Organizacional }\end{array}$ \\
\hline Processos Corporativos & Processos Corporativos & & $\mathbf{X}$ & Alto & Excelente & Formalismo & $\begin{array}{l}\text { Atenção aos } \\
\text { Detalhes } \\
\end{array}$ \\
\hline Planejamento Estratégico & Gestão Empresarial & $\mathbf{X}$ & & Baixo & Regular & Hierarquia & Estabilidade \\
\hline Gestão Empresarial & Gestão Empresarial & & & Medio & Regular & Hierarquia & Estabilidade \\
\hline Gestão Financeira e Contratual & Gestão Empresarial & & & Medio & Regular & Formalismo & Estabilidade \\
\hline Gestão de Negócios & Politica Comercial & & & Alto & Boa & Formalismo & Estabilidade \\
\hline Gestão de Serviços & Processos Corporativos & & & Alto & Boa & Formalismo & Estabilidade \\
\hline Gestão de Projetos & Processos Corporativos & & & Medio & Boa & Formalismo & Estabilidade \\
\hline Gestão de Infra-Estrutura & Processos Corporativos & & & Alto & Boa & Formalismo & Estabilidade \\
\hline Gestão de Pessoas & Satisfação no Trabalho & & & Medio & Regular & Paternalismo & Equipe \\
\hline Responsabilidade Social & Programas Sociais & & & Medio & Regular & $\begin{array}{l}\text { Postura de } \\
\text { Espectador }\end{array}$ & Resultados \\
\hline Desenvolvimento Pessoal & Desenvolvimento Pessoal & & & Baixo & Regular & Impunidade & Equiupe \\
\hline Desenvolvimento Gerencial & Lideranças/Desenv.Gerencial & & & Baixo & Regular & Paternalismo & Pessoas \\
\hline Marketing & & $\mathbf{x}$ & & Baixissimo & Ruim & $\begin{array}{l}\text { Postura de } \\
\text { Espectador }\end{array}$ & Resultados \\
\hline Missão Corporativa & Inovação e Excelência & & $\mathbf{X}$ & Alto & Excelente & Aventureiro & Inovação \\
\hline Gestão de Tecnologia & Processos Corporativos & & & Alto & Boa & Formalismo & Estabilidade \\
\hline $\begin{array}{c}\text { Revisão de Processos } \\
\text { Corporativos }\end{array}$ & Burocracia em Excesso & & $\mathbf{X}$ & Baixo & Ruim & Formalismo & $\begin{array}{l}\text { Atenção aos } \\
\text { Detalhes }\end{array}$ \\
\hline $\begin{array}{l}\text { Alinhamento à Políticas de } \\
\text { Governo }\end{array}$ & Influência Política & & $\mathbf{x}$ & Alto & Regular & Hierarquia & Estabilidade \\
\hline- & Comprometimento & & $\mathbf{X}$ & Baixo & Ruim & Impunidade & Equipe \\
\hline- & Relação Trabalhista & & $\mathbf{X}$ & Baixo & Ruim & Espectador & Pessoas \\
\hline- & Integração das unidades & & $\mathbf{X}$ & Baixo & Ruim & $\begin{array}{l}\text { Personalismo e } \\
\text { Malandragem }\end{array}$ & Equipe \\
\hline- & Foco no Resultado & & $\mathbf{X}$ & Baixo & Regular & Aventureiro & Resultados \\
\hline
\end{tabular}

Quadro 7 - Mapeamento dos Traços da Cultura Organizacional do SERPRO 
No que cabe aos traços da cultura organizacional, o SERPRO apresenta o seguinte quadro:

- Inovação e assunção de riscos: Apresenta um nível de maturidade elevado no que cabe a Inovação e assunção de riscos, onde continuamente se superam novos desafios do mundo de Tecnologia de Informação, por uma característica de existir o gosto pelo desafio, valor compartilhado por muitos funcionários, além de seu comprometimento com bons resultados. Há a percepção de que inovação é um elemento da cultura da empresa, baseado na fala: "Sem nenhuma dúvida, deve-se admirar a criatividade das soluções do SERPRO no campo da TI.”.

- Atenção aos Detalhes: O SERPRO possui processos que estimulam seus funcionários a serem rigorosos e detalhistas em seu trabalho, porém, em algumas situações percebe-se o engessamento do atendimento às demandas do cliente, onde o processo acaba se tornando mais importante que o resultado, pelo menos sob a percepção de alguns entrevistados: "Muito papel a ser prenchido com pouca utilidade. As metodologias utilizadas nos processos corporativos precisam ter como foco a utilidade.".

- Orientação para os resultados: Devido a um parcial desalinhamento e desintegração entre as unidades da empresa (negócios, produtos e serviços) há uma busca por resultados curtos, imediatos, que comprometem o cumprimento rígido de certos ritos e processos corporativos, sendo que esses em alguns momentos acabam, mesmo sendo bastante estruturados e potencializadores de bons resultados, engessando o processo de atendimento ao cliente, gerando uma situação dialética entre as unidades. No que cabe ao imediatismo ou urgência do resultado e na forma como ele ocorre, há quem entenda que fatores políticos afetam negativamente esta questão, considerando as seguintes falas dos entrevistados como "Normalmente os prazos são políticos (para ontem) “ ou "A influência política no SERPRO prejudica a execução das atividades da empresa. O nosso trabalho é essencialmente técnico.” ou ““"As questões políticas prejudicam quando a análise técnica é desconsiderada em função de decisão política, que fica mascarada na empresa como decisão estratégica.”. Mesmo diante do cenário supracitado, vale reforçar que o SERPRO mantém uma posição de destaque e até orgulho, perante os próprios funcionários, em termos de resultados e soluções, baseado em falar geralmente expressas como: "Aprecio a 
contínua inovação da empresa" e "Aprecio a magnitude dos projetos tocados pela empresa".

- Orientação para as pessoas: Ao longo da história do SERPRO, o apreço e atenção aos colaboradores da empresa tem se intensificado, até mesmo por uma trajetória política do Brasil, que saiu da ditadura, alcançou um estágio neoliberal e no momento tem um enfoque social bastante reforçado. Porém, por questões de influência política e contínuas trocas de diretoria e direcionamento empresarial, ainda ocorre uma descontinuidade abrupta em ações previamente planejadas, que gera um impacto ruim aos funcionários, que se sentem um pouco "anulados" até que se readequem às novas diretrizes da nova diretoria em questão. Ainda há o personalismo citado por Robbins (2005), como percebido pela fala "O ambiente de trabalho no SERPRO permite um clima de camaradagem e cooperação muito grande entre as pessoas e isso tem um efeito positivo no trabalho.”. Apesar do aspecto de camaradagem existir, ele está associado a um clima de cooperação e união entre várias equipes, mesmo diante de um cenário de rigidez no cumprimento dos processos corporativos, o que é mesmo até percebido pela fala "O ambiente de trabalho no SERPRO permite um clima de camaradagem e cooperação muito grande entre as pessoas e isso tem um efeito positivo no trabalho. A falta desse ambiente descontraído e pouco competitivo é uma das maiores reclamações das pessoas que saem do SERPRO para trabalhar em outras organizações públicas ou privadas.".

- Orientação para a equipe: O trabalho em equipe no SERPRO é bastante estruturado, devido à uma estrutura ampla que a empresa apresenta, tendo extensões regionais em diversas capitais brasileiras. A estruturação do trabalho em equipes é vital nesse modelo capilarizado e a dinâmica de trabalho das equipes é muito bom, no que cabe ao relacionamento interpessoal, muito embora este também seja prejudicado por algumas amarras dos rígidos processos corporativos. Essa rigidez e ampla estrutura acaba também gerando uma percepção de feudos, conforme posição de um dos entrevistados sobre o que precisamos melhorar "Integração entre as diversas áreas que atendem nossos clientes, para que atuemos como uma só empresa e não como várias empresas dentro de uma.”. Há também a percepção que nas unidades regionais da empresa (localizadas fora de Brasília) existe uma união maior entre os colaboradores, baseada na fala "Uma coisa admirável no Serpro, principalmente nas 
regionais, é o relacionamento entre os empregados, onde o trabalho em equipe e a colaboração na busca das melhores soluções e práticas são naturais.”. Em geral, esses colaboradores têm uma origem comum ou próxima, em termos de naturalidade regional (o que nem sempre ocorre em Brasília, já que possui colaboradores de várias naturalidades), o que provavelmente potencializa esta união, onde a maioria compartilha de valores e costumes comuns e que reforça a abordagem de Castro (2002), que comenta que mesmo diante de uma cultura nacional, principalmente num país bastante miscigenado como o Brasil, há expressões e costumes regionais que acabam influenciando de forma diferenciada determinados grupos dentro de uma mesma empresa.

- Agressividade: Devido a uma influência subjetiva e política na indicação de alguns cargos, normalmente atrativos em níveis financeiros, naturalmente há uma concorrência entre os colaboradores. Essa influência é percebida por posições como porém, não parece ser de percepção dos funcionários que esta concorrência seja tão agressiva como normalmente acontece em empresas privadas, onde $\mathrm{o}$ fator estabilidade não é tão forte.

- Estabilidade: O SERPRO mantém-se como referência de Tecnologia de Informação a partir do seu contínuo envolvimento, em linhas estratégicas, com diretivas e implementações de ações do governo no âmbito de TI. A estabilidade que a empresa demonstra basicamente se volta para o ritmo de diretivas governamentais, mas que também não impede a inovação contínua em soluções apresentadas para atendimentos das demandas do Governo Federal. Esse alinhamento às diretivas de Governo se reflete na contribuição e participação de projetos importantes, inclusive à longo prazo e independentes de partidos políticos, percebidos na falas coletadas durante a entrevista sobre a influência política na empresa: "A influência política ajuda para conseguir apoio para programas fundamentais para o Governo Brasileiro, ajuda." e "O SERPRO, como uma empresa de tecnologia do Governo Federal tem que continuar atuando de forma independente de política partidária e sim da estratégia de governo.". Sobre a estabilidade do próprio funcionário do SERPRO, diferentemente de um perfil comumente encontrado no cenário do serviço público, conforme comentado no tópico 2.5, o funcionário do SERPRO não se percebe como um servidor público efetivamente (ao estilo percebido comummento como 
acomodado e desmotivado), o que se percebe pela fala: O empregado de Serpro de um modo geral é motivado e comprometido, não se comparando ao servidor público, aliás no Serpro ninguém se vê como um servidor público.”. É claro que há exceções ao longo de uma empresa que cerca de 9000 funcionários, porém, é importante reforçar que talvez pelo histórico da empresa, baseado em inovações e bons resultados para o governo, o valor "gosto por desafios" comumente defendido pela empresa, ainda tenha se internalizado em seus funcionários, desde novos até os mais antigos que já vivenciaram fases extremistas e mais liberais dentro do país e da própria empresa. Isto reforça a abordagem de Freitas (2002) que afirma que as organizações modernas são produtos da história e do tempo das sociedades onde se inserem. 


\section{CONSIDERAÇÕES FINAIS}

No estudo realizado podem-se observar os principais traços da Cultura Organizacional do SERPRO, baseando-se em visões da organização e de seus próprios colaboradores, e nos traços característicos da cultura nacional e do estilo brasileiro de administrar. Aspectos do serviço público também foram contemplados na análise de conteúdo.

Apesar do SERPRO ser uma empresa pública desvinculada da administração direta, dependendo basicamente de suas próprias receitas para custear sua própria existência e realizar investimentos, ele não deixa de receber influências, em seus diversos níveis empresariais (estratégico, tático e operacional), características do setor público, como a política, e do próprio estilo brasileiro de administrar, a da amizade.

Ao contrário de uma tradicional visão do servidor público, por vezes descomprometido, desmotivado e pouco inovador, no SERPRO, a excelência pelo processo e a inovação em termos de soluções tecnológicas parecem ser unanimidade em seu contexto organizacional, porém, um movimento interno favorável a uma melhoria urgente no trabalho inter-unidades (melhor integração) e a um processo mais flexível e menos burocrático, focado em dar resultados de alta qualidade em menor prazo, tem crescido bastante. Percebe-se ainda que há, tanto profissionais mais jovens como os mais antigos, um anseio de melhor alinhamento estratégico em todos os níveis, uma vez que as camadas mais operacionais acabam por executar atividades sem ter a visão geral da missão da empresa.

Há de balancear o rigor de alguns processos corporativos com a necessidade de rápido atendimento ao cliente, que nem sempre tem a percepção do benefício ou efetiva utilidade de alguns procedimentos, o que leva a desgastes internos, onde unidades de negócio desejam atender as demandas do cliente, mas não conseguem fazê-lo a tempo em razão dos rígidos processos internos.

Há um destaque para a visão que muitos funcionários têm sobre a importância da empresa no contexto político e nacional, dada a relevância de seus projetos e resultados para o governo federal, independente de uma abordagem político-partidária, e sim, alinhada a estratégia de governo como um todo. Esta relação próxima ao governo ajuda a própria empresa a participar de projetos importantes e até na concepção e padronização de diretivas de Tecnologia de Informação em âmbito nacional.

O paternalismo e o personalismo ainda podem ser caracterizados no contexto da empresa. $\mathrm{O}$ primeiro ocorre normalmente com um verniz político, já que a nomeação de muitos cargos 
gerenciais ocorre por indicações políticas e acabam gerando compromissos fortemente hierárquicos, como do tipo : "Manda quem pode, obedece quem tem juízo.". O segundo ocorre principalmente quando as interações entre as unidades da empresa se dão por meio da camaradagem, onde mais vale você saber com qual pessoa falar do que com qual unidade tratar. Desta forma, o relacionamento entre pessoas de unidades diferentes acaba favorecendo consideravelmente para que o processo de atendimento supere algumas amarras burocráticas, bastante questionadas nessa relação inter-equipes.

Diante de um cenário onde há funcionários motivados em gerar soluções inovadoras e importantes para o país, onde há uma busca pela excelência, e onde também há uma necessidade de se dar respostas mais rápidas à sociedade brasileira, que em ultima instância é a maior afetada e interessada pelas soluções do SERPRO, parece ser necessária e crítica (com base nas próprias entrevistas) uma simplificação de alguns processos corporativos, balanceando melhor o controle das atividades e o resultado delas.

De maneira geral, observa-se que a dinâmica organizacional da empresa é afetada pela dinâmica social e política brasileira, seja no seu aspecto positivo ou negativo, relacionado aos vícios da administração brasileira: formalismo em excesso, "jeitinho" e outros elementos supracitados neste trabalho. Uma transformação abruta da empresa talvez nunca aconteça de forma desagradada do fator social brasileiro, porém, é com uma contínua auto-análise organizacional e o delineamento da sua identidade organizacional e de sua influência cultural, que oportunidades de melhoria surgirão e a implementação de novas práticas, que transformem gradativamente seu próprio contexto organizacional, acontecerão. 


\section{REFERÊNCIAS}

CASTRO, Celso Pinheiro de. Sociologia aplicada à administração. São Paulo: Atlas, 2002.

CHIAVENATO, Idalberto. Gestão de Pessoas. Rio de Janeiro: Editora Campus, 2004

DaMATTA, R. A casa e a rua: espaço, cidadania, mulher e morte no Brasil. São Paulo: Brasiliense, 2005.

FREITAS, Maria Estér de. Cultura Organizacional: identidade, sedução e carisma?. $3^{\mathrm{a}}$ Ed. Rio de Janeiro: Editora FGV, 2002.

FREYRE, G. Casa grande e senzala. 13ª ed. Rio de Janeiro: José Olympio, 1966.

JOHANN, Silvio Luiz. Gestão da cultura corporativa: como as organizações de alto desempenho gerenciam sua cultura organizacional. São Paulo: Saraiva, 2004.

LÜDKE, M. Métodos de coleta de dados: observação, entrevista e análise documental. In: LÜDKE, M.; ANDRÉ, M. L. Pesquisa em educação: abordagens qualitativas. 6. reimp., São Paulo: EPU, 1986. cap. 3 , p. 25-44.

MOTTA, Fernando C. Prestes; CALDAS, Miguel P. Cultura Organizacional e Cultura Brasileira. São Paulo: Atlas, 1997

PRADO Jr., C. Formação do Brasil contemporâneo. 19ª ed. São Paulo: Braziliense, 1969.

PUGLISI, Maria Laura; FRANCO, Barbosa. Análise de Conteúdo. Brasília: 2003

ROBBINS, Stephen P.. Comportamento Organizacional. 11 a ed. São Paulo: Pearson Prentice Hall, 2005 ,

TROMPENAARS, Fons. Nas ondas da cultura: como entender a diversidade cultural nos negócios. São Paulo: Educator, 1994.

VERGARA, Sylvia Constant. Começando a definir a metodologia. In: pesquisa em administração. 3 ed. São Paulo: Atlas, 2000.cap. 4. _Projetos e relatórios de 